\title{
Developing a Signature Pedagogy and Integrated Support Model for First-Year Teacher Education Students Studying at a Regional University
}

\author{
Ingrid Harrington $^{1}$, Robert Whannell ${ }^{1} \&$ Tim Bartlett-Taylor ${ }^{1}$ \\ ${ }^{1}$ School of Education, Faculty of Humanities, Arts, Social Sciences, Education (HASSE), University of New \\ England, Australia \\ Correspondence: Ingrid Harrington, School of Education, Faculty of Humanities, Arts, Social Sciences, Education \\ (HASSE), University of New England, Australia.
}

Received: May 24, 2021

Accepted: August 15, 2021

Online Published: August 17, 2021

doi:10.5430/ijhe.v11n1p126

URL: https://doi.org/10.5430/ijhe.v11n1p126

\begin{abstract}
The Australian regional university where this pilot study was completed is confronted with a number of demographic factors that challenge the delivery of effective student support and engagement. In 2020, the teacher education student cohort comprised of approximately 5,100 students, with $82.6 \% 25$ years of age or older, $20.3 \%$ identified as having a low SES background, $43.7 \%$ being first-in-family, and $96.1 \%$ studying off-campus. Student demographic characteristics such as these are commonly cited as factors that contribute to increased challenge in completing tertiary study (Grebennikov \& Shah, 2012; Li \& Carroll, 2020). The attrition rate for commencing students for the period from 2010 to 2018 ranged between $24.6 \%$ and $36.2 \%$. While these demographic characteristics are largely objective in character and may not be able to be addressed by university-based intervention, the nature and quality of the learning environment students' experience is able to provide the best opportunity for them to successfully complete their tertiary study endeavours, despite their personal context and backgrounds. One factor that has been identified as critical to the success of commencing students, particularly those from non-traditional backgrounds, is the nature of their relationships with, and the academic environment established by the academics teaching first-year units (Farr-Wharton, Charles, Keast, Woolcott, \& Chamberlain, 2017).
\end{abstract}

Keywords: initial teacher education, first-year transition

\section{Introduction}

\subsection{The Problem}

A 2019 review of the School of Education (SOE) at the university where this project was conducted identified the need to revisit how first-year units were delivered, with a renewed focus on improving the overall student experience to positively impact retention. Student retention has been an ongoing challenge for the school and wider institution and a variety of initiatives had been adopted to address the issue. The review identified shortcomings in the nature of the support available to first-year students and the lack of a consistent, collaborative pedagogical approach used in the delivery of first-year units. Consequently, the SOE commenced a project entitled the Commencing Student Success Project (CSSP) that aimed to change the way in which Unit Coordinators (UC) engage with and support students in their first year of study. The project sought to address issues identified within the review through the raising of UCs awareness of the need for and their responsibility to proactively build positive relationships with their students and through the identification and implementation of pedagogical practices that would best support mature aged, first-year students in transition to tertiary study. While the student cohort of the SOE has a high proportion of non-traditional students, the project was intended to enhance the experience of all first year students.

\subsection{Literature Review}

Stone and Springer (2019) argue that there "is evidence to indicate a supportive and engaging online teaching and learning environment, can help to mitigate...difficulties and lead to increased student retention" (p. 147). The question raised by Brown (2020) in relation to the current state of adult education in Australia seems particularly relevant to the cohort of adult learners who enrol in the initial teacher education courses offered through the SOE, namely "Is ... our own thinking about what adult education is today, fit to meet the needs and challenges of our 
world?" (p. 8). Falasca (2011) argued that, while there has been much written about barriers to adult learning, there has been limited focus on how to deal with these barriers from an organisational and institutional perspective.

The literature consistently reports how attending university is stressful for students: Stallman (2010) found that 84\% of Australian students reported elevated distress, and 19\% reported high distress compared to $3 \%$ of the general population. This stress can be generated by personal factors, institutional factors, or the intersection between the two. For example, high levels of paid work, additional family responsibilities or living far from campus are potential causes of stress, which can influence student success by impeding student engagement (McMillan, 2005).

The level of students' academic self-efficacy influences their motivation and learning through its impact on persistence, goal setting and the use of self-regulatory strategies (Bandura, 2001). High self-efficacy levels increase student engagement and success and, in return, engagement and success increase self-efficacy (Schunk \& Mullen, 2012). Within tertiary education settings, 'belonging' is described as the students' connectedness to the institution, staff and other students (L. Thomas, 2012) taking into consideration the discipline being studied i.e. the degree of fit an individual perceives between their individual habitus, and that of the institution. The strategies developed and included in the CSSP were intended to enhance these aspects of students' first-year experiences.

UCs engaged in the delivery of first-year units play a key role in supporting students in the development of students' self-efficacy, positive levels of emotional experience and well-being associated with learning and transition, and a sense of connectedness to the institution (Kahu \& Nelson, 2018). UCs typically have a well-developed sense of academic identity, with an associated identity role developed over many years, firstly as a student, but also as an academic and educator (Stryker \& Burke, 2000). The project supported participants as they interrogated the current nature of their professional and personal identities as a UC, and to potentially develop these to incorporate new understandings, different paradigms, and altered behaviours towards their students (R. Whannell \& Whannell, 2015).

\subsection{The Research Questions}

The focus of this paper, which describes the first six months of the project, was on the following research questions:

1. What are the current attitudes, beliefs and understandings for SOE Unit Coordinators and support staff, in relation to their role as educators of first-year students?

2. What barriers exist for SOE Unit Coordinators and support staff in changing their attitudes, perceptions and pedagogical approach for teaching first-year students?

3. How can SOE Unit Coordinators enhance the experience of first year students through the implementation of innovative pedagogical practices?

What follows is a summary of the initial development process for the project, from the initial decision to conduct the project and the reasons it was required, to the identification of 15 key principles entitled "Basic Elements", that will be incorporated into all first-year units in the SOE. This following section describes the institutional context experienced by first year students in the SOE with a focus on the support structures available.

\section{First-Year Student Experience in the School of Education}

\subsection{Current First-Year Transition Process for SOE Students}

Prior to the commencement of the CSSP, the first point of engagement and support for a commencing initial teacher education student is their experience with the universities' enrolment support structures: the Enrolment Support Mantle. This mantle is focussed on getting the student enrolled in their choice of course, and set up with the correct services required to commence study.

Once the initial enrolment and orientation process are complete, two main cores of support are available: i) the Outer Core; and ii) the Inner Core. The Outer Core houses the support for students outside of the units where teaching and learning occurs. This Outer Core comprises:
i. University Orientation
ii. Faculty level academic and pastoral support i.e. a First-year Advisor
iii. Professional Experience Support - Placement matching and support
iv. Enrolment support - Student Success
v. University-wide Services and Resources, external to Faculty student support - Counselling, Academic Skills Office, Residential Colleges, Library, Outreach program
vi. Within Faculty administrative support 
The Inner Core houses the support for students once enrolled in units and involved directly in teaching and learning process, and comprises:

\section{i. Unit Coordinator \\ ii. Staff involved in teaching and assessment}

The transfer from the Outer to the Inner Core must be completed successfully within a short time frame as first-year students engage and connect, or conversely, disconnect with their tertiary institution within the first two to six weeks of study (Barnes, Macalpine, \& Munro, 2015). These Inner and Outer Cores both currently function at the institution, yet a disconnect of how to best utilise the cores cohesively had been identified in the review of the SOE. While the university devotes extensive time and resources to the provision of support services, as pointed out by Roberts, Boldy, and Dunworth (2015, p. 134), "the valuing of a service in principle, and a belief in the importance of its availability, does not necessarily lead to a view that a given service, as experienced, is useful".

The SOE review identified issues due to the lack of cohesion in a number of aspects of student support described above, the first being the lack of integration between the Inner and Outer Cores, where there was a lack of communication and engagement between academic and teaching staff in the units and the support staff outside the SOE, a lack of engagement between the UCs of first-year units, and finally, within units where there was a lack of communication and relationship between university academic staff and students. The model described above requires a student to negotiate an enrolment and orientation process which is largely conducted by personnel who are not academics and who are not involved in the delivery of academic units. This is followed by entry in up to four different academic units, each presented by a UC with his/her own approach to engaging with and providing support for students.

Within the teaching and learning sphere (Inner Core), the flow of unit information separates into four distinct Unit Moodle sites in the universities Learning Management System (LMS), with four individual academics as Unit coordinators with potentially four different styles and approaches to teaching, and ways they relate to and engage with students. The SOE review identified this situation as a point of disconnection that created confusion and could be overwhelming for some students. The nature of the disconnection can be simple: who to speak with for advice around school professional experience etc., or can be more in-depth: enrolment and progression issues, counselling support, writing skill improvement, etc. further creating issues for students not understanding the connection between unit support and general support. Kift and Moody (2009) argue that "at the very minimum, if we expect first year students to become independent and self-managing learners, both teachers and students need to be supported to aid the early development and acquisition of tertiary assessment literacies" (p. 1). At first-year level certain processes may not be clear to students and UCs. Richardson (2011) argues that a "mismatch between the perceptions of teaching staff and students is likely to lead to widespread disappointment among students" (p. 3) with negative impact on student outcomes.

Another issue for the current first-year student that was identified in the SOE review, was the lack of a core philosophy or teaching and learning framework that underpins teaching, and would provide a consistent learning environment across all first-year units. This lack of an underpinning philosophy manifests as a dissimilar collection of units espousing mixed modes of practice embedded in differing student expectations, and, in some cases, a belief on the part of the academic of being the 'gatekeeper' (Posselt, 2016). Gasiewski, Eagan, Garcia, Hurtado, and Chang (2012), in a large scale USA study, found that students were "more engaged in courses where the instructor consistently signalled an openness to student questions and recognizes her/his role in helping students succeed" (p. 229). Where there is a widespread mismatch between the perceptions of staff and students, widespread disappointment among students may result (Richardson, 2011). They also argue that faculty should "move away from gatekeeping strategies where few are expected to do well and instead move toward practices that ensure more students can succeed" (p. 251). It was acknowledged in the SOE that some units were being successfully taught with a strong student focus on their success and with the knowledge of how to support them, however, significant improvements needed to be made at a systemic level to include all unit offerings.

The model for supporting first-year students and building an exceptional experience for them aimed to ensure that the two cores could operate amongst and within each other, transferring information back and forth about the student to ensure all support structures are well informed and can be utilised at appropriate times.

\subsection{Proposed Structure for Changes to Student Experience}

Considering the literature relevant to the first-year experience and the challenges identified by the review of the SOE, a number of principles were identified upon which to base the CSSP project. The principles were developed collaboratively by the academics leading the project and approved by the executive of the SOE. These principles 
place the student at the centre of the transition process, surrounded by a layer of support which functions to provide support for both the student and academic staff engaged in the delivery of academic units. The principles developed were:

Principle 1: From the time of enrolment to the commencement of the first trimester, the student passes through the outer academic support services core, where appropriate, and supportive orientation and "student-in-transition" support is provided within the Enrolment Mantle and Outer Core.

Principle 2: Upon commencement of the academic trimester, the experience of the student is determined by what happens within the units in which they are enrolled, principally through:

- Standardised processes for timely engagement by academic staff;

- Efficacious engagement with the curriculum, delivered either on-campus or via Moodle; and

- Positive, enabling engagement with assessment.

Principle 3: The UC is attributed initial and primary responsibility and accountability for the quality of the students' experience and the outcomes achieved. In circumstances where the student does not feel comfortable in liaising with the UC, then the student has the option and recourse to seek support from the other numerous supports available. This responsibility and accountability should not be automatically shifted to the support services personnel.

Principle 4: During the trimester, responsibility and accountability for student learning and support lies with the UC. Support is provided primarily within the academic structure and personnel of a Unit. Support from the Outer Core is utilised when the support requirements are either not available from or exceed the capacity of the Unit's academic staff, or if the student bypasses the Inner Core for other reasons.

Principle 5: Students access support services outside of the academic structure on a needs and referral basis. Where such supports are accessed, the nature of the support is advised, through the First-year Director if anonymity is required, to the Unit Coordinator/s as appropriate, considering the privacy and educational requirements applicable.

\section{Methodology}

The project was commenced in the second trimester of 2020 after the granting of ethics approval with seven first-year UCs agreeing to voluntarily participate in the project. Participants ranged from early career academics, with less than three years' experience, to an Associate Professor with over 20 years' experience. The initial phase of the project, which is reported in this article, was conducted between July and December 2020.

An action research methodology (Stringer, 2008) is being used for the project, and the study will be completed in the following phases. Data collected will involve a mixed method approach (Axinn \& Pearce, 2006), where quantitative data from Moodle analytics and participant surveys will be used in conjunction with qualitative data from participant surveys. The following action research cycle will be completed using the following phases:

Phase 1: Investigating the current beliefs, attitudes, identity and role of UCs and support staff.

Phase 2: Initial intervention training and collaborative development of the signature pedagogical model. The central concepts of adult learning principles (Weuffen, Andrews, \& Roberts, 2020) were embedded in the intervention training.

Phase 3: Implementation of the pedagogical model.

Phase 4: Analysis of data and evaluation of Phases 1 to 3.

Phase 5: Based on the analysis of evidence completed in Phase 4, the signature pedagogical model and training program will be further developed, with the cycle repeated in subsequent trimesters.

Depending upon the outcomes from the first cycle of action described in Phases 2 to 5 , the research will complete an identical second cycle as per the action research methodology. It is expected at this point that the project will involve a minimum of two iterations: the first in T3, 2020 and the second in T1, 2021. A third iteration in T2, 2021 may also be completed depending upon the outcomes of the project at the end of the second iteration.

\subsection{Project Description and Integrated Data Collection}

\subsubsection{Initial Survey}

An initial anonymous survey was completed using Qualtrics. The survey collected data in relation to the current beliefs, attitudes and role of UCs. It consisted of eight Likert items asking participants to rank how important it was for them to know certain information about commencing students in their unit; previous academic performance, 
academic self-efficacy, connectedness to the institution, overall well-being, engagement with other students, engagement with the UC, engagement with Moodle and engagement with the universities' support services. Items used a seven-point scale, from Not Important to Very Important. Open-ended items were also provided to allow participants to describe how they obtained information about their first-year students in relation to these same areas. Examples of the items provided are shown.

- Students in your unit present as unique individuals with varied backgrounds, experiences and knowledge. What do you use, if anything, to evaluate the following for commencing students that enrol in your unit?

- What Moodle techniques, pedagogical strategies and personal approaches do you use when teaching commencing students to develop each of the following areas?

- Who do you consider is primarily responsible for responding to a request for assistance from a commencing student? Why?

Each item provided space for response in relation to previous academic performance, academic self-efficacy, connectedness to the institution, overall well-being, and engagement with others, the UC and other staff.

\subsubsection{Intervention Training}

Participants were provided with access to an online training program in the learning management system, Moodle. Two synchronous Zoom sessions were then held, each running for approximately three hours, to support the learning materials. The theoretical framework used for the intervention training is described more fully later in this article.

\subsubsection{Post Intervention Training Collaboration to Develop a First-Year Unit Signature Pedagogy}

Following the completion of the intervention training, participants and presenters engaged in an online collaborative process to develop a signature pedagogy for first-year units. A component of the collaboration involved UCs having access to all involved Moodle units coordinated by the participants in the project. Those aspects that were collectively considered appropriate to support the outcomes of the CSSP were identified and new pedagogical components were proposed.

\subsubsection{Final Interview}

Following the development of the signature pedagogy document, UCs were provided with the following interview prompts by email.

Q1. How did the CSSP training impact on your thinking as a UC and how you:

- communicate/view students?

- design and access information on my Moodle site?

Q2. What is the biggest benefit you consider your involvement in the CSSP project to-date has been?

Q3. What do you consider the barriers have been to engaging with the CSSP up to this point?

\section{Results and Discussion}

This section will present an analysis of the data collected in the initial phases of the project and, using the action research phased approach, describe who the analysis was implemented throughout the first trimester of delivery. The section commences with a summary of the first data collection, which examined Unit Coordinators views about teaching first-year students. This will be followed by a description of the development of the theoretical framework for the intervention training for Unit Coordinators and the literature based upon which this training was based. The final section will describe the signature pedagogical framework developed collaboratively by the project participants.

\subsection{The Initial Survey}

The UCs responses to the initial survey where they reported on the importance of knowing various aspects of the students' background and learning context were analysed.

\subsubsection{Importance at the Institutional Level}

UCs rated limited importance on institutional level matters, particularly the students' connectedness to the institution. Kift, Nelson, and Clarke (2010) propose three principles that should guide initiatives for enhancing the first-year experience, the third being "creating a sense of belonging through involvement, engagement and connectedness with their university experiences" (p. 4). Connectedness to the institution using technology as the means to relate to teaching staff and other students has also been identified as a key component of supporting first-year students studying by distance (Andrews \& Tynan, 2012). 


\subsubsection{Importance of Students' Academic Preparedness}

The importance UCs placed on students' previous academic performance and their academic self-efficacy were considered to be at relatively low level, particularly the students' previous academic performances. The first open-ended item in the initial survey asked participants to describe how they evaluated commencing students' previous academic performance and their level of academic self-efficacy. Four participants stated explicitly that they did not evaluate previous academic performance, while two indicated they used the first assessment task in the unit. While no participant had a specific mechanism in place to evaluate academic self-efficacy at the commencement of the unit, three indicated that they considered this during their interactions with students as a part of their ongoing engagement with them.

- [Academic self-efficacy] is not something I set out to evaluate at the commencement of a unit, but it is something that I would be considering as issues arise for students throughout the teaching period.

- Again, knowing where students are and how they are progressing means I can place better supports within the unit to meet students learning journey needs. So, I will engage in discussion boards and also work to highlight the importance of academic literacy skills

- I monitor any emails/posts where students indicate that they are not feeling confident in their ability to do something or unsure about their understanding and I follow-up with those students, usually through Moodle to encourage others to follow suit if they feel the same way

What was apparent from the participants' responses was that there was no standard approach available and used within first-year units in relation to early diagnostic assessment, where students who may be ill-prepared to engage with their study were able to be identified at an early stage and provided the support they may require. The importance of the first six weeks of university study after commencement has been identified as a period of high vulnerability for students (Barnes et al., 2015), particularly those from a non-traditional background (P. Whannell, Whannell, \& Allen, 2012).

The first standard in the Australian Institute for Professional Teachers requires teachers to Know Students and How They Learn (Australian Institute for Teaching and School Leadership, 2020). Two key elements of an educator knowing their students would be the students' previous academic performance and their level of academic self-efficacy, particularly at the commencement of a unit, so it appears unusual that such a relatively low importance has been placed on these factors.

This situation suggests that there needed to be two related aspects included in the CSSP to allow individual commencing students' needs to be addressed. Firstly, that UCs attitudes and beliefs about the importance of these aspects needed to be enhanced and their needed to be a documented and understood process that allowed UCs to gather diagnostic assessment data. This situation though, was considered to require a great deal of finesse. Debenham and May (2005) identified early assessment experiences in a tertiary enabling program, which caters generally to non-traditional students, as being of particular importance when they stated that "the first milestone in an enabling program for both students and lecturers is the submission and return of the first assignments [and] it can be asserted ... that the first assignment is surrounded on all sides by anxiety" (p. 89). They also concluded that "initially students are threatened by "academic work" (p. 89). This view is echoed by T. Thomas et al. (2018) for students in the first-year of study, where they argued that "poorly designed assessment can be demotivating and may even cause students to withdraw from university" (p. 1).

As a consequence, it was considered that the CSSP should include a process of diagnostic assessment, but that the approach used would provide the following:

- UCs had access to the evidence held by the university in relation to the student, including their previous school academic results and enrolment application;

- Units would commence with an engaging activity that would provide ALL students with a positive experience of learning that would enhance their academic self-efficacy through mastery. It should be noted that this mastery does not need to be done in relation to academically challenging situations (Usher \& Pajares, 2008);

- Any diagnostic assessment task/s used would be integrated into the students' initial engagement with the unit and would be perceived by students as a part of their normal teaching and learning. 


\subsubsection{Importance of Students' Engagement in the UCs Unit}

The UCs responded to items relating to students' engagement with matters that directly related to teaching and learning in their own unit. The data reflected that the students' engagement with Moodle was rated as being the most important aspect to UCs, and was rated higher than any other factor measured in the study.

The first open-ended item asked UCs to describe how they evaluated commencing students' engagement with Moodle. Of the seven responses, only three described a specific strategy whereby they used the data available in Moodle to measure engagement.

- This is monitored through Moodle activity.

- Via the Moodle analytics.

- I have worked hard to ensure that students engage fully with the online learning content by designing hurdle tasks. They cannot unlock topics or progress to submission of their assignments unless they pass each topic quiz. This has increased engagement significantly.

The remaining responses described the importance of engagement, but were general in nature.

- Very important!! If students don't engage with Moodle they will fall behind very quickly!

- It is where the learning materials and activities are.

- I do not evaluate this for each student individually but I always check that there is a relatively high percentage of students using the various resources (via Gismo)

- I have Forums where students can post to me. I list my personal mobile, email (obviously), I record a video of me babbling about the unit as an introduction, and then each for the two assignments.

Considering the role that Moodle, the institution's LMS, has as the vehicle used to deliver teaching and learning and the primary tool for communication between academic staff and students, this does seem quite surprising. Of particular importance is the lack of a consistent response to the item that would indicate a clearly established, and perhaps required, practice that was known to the participants to evaluate student engagement in the initial transition into first-year units. Considering the institution has a long experience with online learning and over $90 \%$ of students in the SoE study online, this appeared as a substantial issue. Developing a process to support UC's capacities to use Moodle and the evidence it provides of student engagement, was considered essential to include in CSSP as it progressed.

\subsection{Intervention Training and Theoretical Framework}

The purpose of the intervention training was to address five key objectives, namely:

1) To provide UCs with a framework to support their understanding of the challenges of first-year university students in transition.

2) To provide UCs with a framework to support their own experiences of involvement in the CSSP and how it might challenge their beliefs, attitudes and related identity in relation to their academic role.

3) To provide UCs with a common framework to understand how they could evaluate their presence and relationships with students.

4) To introduce UCs to the CSSP project (described previously) and provide them with an understanding of their role.

5) To develop the key aspects of the signature pedagogical approach that they would use commencing in trimester $3,2020$.

The signature pedagogy of student support developed was based upon evidence-based aspects of the literature, with the focus on teacher presence and engaging pedagogical design supported by Stone and Springer (2019). The general background to the first-year students' transition experience was based on the literature of Kahu and Nelson (2018), with its focus on interrogating self-efficacy, emotion, belonging, and well-being.

Self-efficacy: Self-efficacy is an individual's belief in their capacity to perform a given task, stemming from a cognitive appraisal of personal and environmental factors. Academic self-efficacy influences student motivation and learning through its impact on persistence, goal setting and the use of self-regulatory strategies. High self-efficacy increases student engagement and success and, in return, engagement and success increase self-efficacy (Schunk \& Mullen, 2012). 
Emotion: The first year is a particularly emotional time for students. For non-traditional students, the gap between their existing identities and experiences and the expectations and requirements of the institution may result in more negative emotions. While some anxiety can be a motivating force leading to greater behavioural engagement, chronic or extreme anxiety can have a negative impact and lead to disengagement and withdrawal (Kahu, Stephens, Leach, \& Zepke, 2015).

Belonging: In education settings, belonging is described as the students' connectedness to the institution, staff and other students (L. Thomas, 2012), as well as the discipline being studied; the degree of fit an individual perceives between their individual habitus and that of the institution. The need for belonging, to have positive interpersonal attachments, is widely recognised as a fundamental human need (Baumeister \& Leary, 1995). Through initiating student supported learning opportunities, friendships also lead to opportunities for students to deepen their engagement: enhance student interest, develop positive learning behaviours, and increase cognitive understanding.

Well-being: Attending university is stressful (Stallman, 2010), and this stress may be caused by personal factors, institutional factors, or the intersection between the two. Well-being is more likely to be compromised for students who belong to multiple equity groups (Edwards \& McMillan, 2015). For example, high levels of paid work, additional family responsibilities or living far from campus (all characteristics of non-traditional students) are all potential causes of stress, which can influence student success by impeding student engagement.

To support UCs' understanding of the identity challenges that might potentially arise for both students in the first-year transition and to provide additional background to the work of Kahu and Nelson (2018), and for the Unit Coordinators as they engaged with the requirements of the project, identity theory (Stets, Burke, Serpe, \& Stryker, 2020; Stryker \& Burke, 2000; R. Whannell \& Whannell, 2015) was also presented. This was considered essential to provide a theoretical framework to assist with understanding the process of change in a transitional context.

The model of identity theory presented had previously been used in relation to non-traditional students in the transition to university (Bolton, 2016; R. Whannell \& Whannell, 2015) and in academic collaborations in pre-service teaching contexts (Fraser, Beswick, Penson, Seen, \& Whannell, 2019). A dynamic view of identity was presented, where identities are "always changing (albeit slowly) in response to the exigencies of the situation. Insofar as an identity cannot change the situation...it adapts slowly, gaining control where it can, and adapting where it must" (Burke, 2006, p. 93). The first key aspect of the model presented was the role of emotional experiences of the teaching and learning context and their impact on the level of commitment to academic identity and on underlying attitudes, beliefs and values. Where these emotional experiences were negative, it was argued that the commitment to the identity was reduced and the preparedness to perform the role associated with that identity challenged. For students, this was associated with their transition experiences in general, but assessment in particular during the early stages of transition. The need for appropriate forms as assessment that would provide students with a sense of mastery and the associated positive emotional experiences was emphasised. The role of traditional examination-type assessment during the early transitional period was raised and questioned. For UCs, it was argued that involvement in the CSSP may challenge their sense of identity as an academic and their understanding of their role with first-year students and give rise to negative, and potentially strong, emotional responses as a consequence.

One theoretical framework that was presented in association with identity theory was attribution theory (Kelley \& Michaela, 1980). The aspect of attribution theory described focused on how the event of student success or failure was interpreted by UCs and how the causes of and personal control over these events were attributed. It was argued that UCs could interpret the cause of student success or failure as either being the result of external, objective forces over which they had no control e.g. financial issues, family challenges, or as something that they could influence through their own actions through creating an engaging, supportive learning environment. The focus for the CSSP was to promote the attribution of student success with UCs personal efforts and the nature of the educational experience students created within their units.

The final foundational theoretical frame described was transactional distance theory (Moore, 1993). This theory was presented to provide a vehicle by which participants could understand and evaluate the nature of the learning relationship between themselves and their students and how transactional distance was influenced by factors within the learning environment.

\subsection{The Signature Pedagogy}

Following the intervention training period, participating UCs and project managers collaborated to develop a signature pedagogy to support first-year students and provide an integrated support model. This resulted in the identification of 15 key concepts named "Basic Elements" that would be implemented in first-year units 
commencing in trimester 3, 2020. One key aspect that arose during the intervention training and was emphasised in the subsequent collaboration was the importance of using Universal Design for Learning (Hall, Meyer, \& Rose, 2012) principles in the units. The final framework developed for implementation is summarised in Table 1.

Table 1. First-year signature pedagogy framework

Central Concept To appear in your unit

1. Use a range of methods to scaffold and assist students with completing assessment tasks.

2. Flexible two to three-week due date submission portal for assessments.

3. Grouping of assessments replacement of tasks that are small and time sensitive i.e. weekly tasks worth $5 \%$

\section{Replacement of Exams}

5. Provide an additional opportunity for students to learn from their assessment efforts and pass the unit. 6. Explicitly illustrate how students can successfully complete assessments.

7. In-unit post-assessment task evaluation to refine teaching and to make future assessments more meaningful.
- Short weekly video communication of what has been covered, what will be covered next week and what you can do to prepare

- Offer one weekly chat session over Zoom

- Welcome to the unit greeting - video

- Video of Assessment explanation

- Have 1-2 student mentors within the units to support student questions.

- $\quad$ A fixed date will be the preferred due date, but the 2-3 week portal period provides the flexibility and no need for students to apply for an extension if they submit the assignment within that period.

- Extensions following UNE extension policy will be required if student needs to submit after the 2-3 week portal is closed.

- Reduction of Regular Weekly Tasks of 5\% to one $15 \%-20 \%$ task over three-four weeks in a module.

- Use of summative quizzes to replace formal exams.

- Assessment resubmission opportunity for failed assessment components

- UCs to provide an exemplar of what a 'good' assessment looks like for each assessment task. Examples may include:

- a de-identified previous paper;

- a template outlining what you expect to see in different sections of the assessment

- Video/screencast explanation of expectations;

- "How to" videos to demonstrate completion of key components of the task;

- Sample responses provided at key junctures in the template;

- Sequencing tasks to build knowledge, skills and CONFIDENCE;

- Provide examples of what is a 'high-range' / 'mid-range' / 'low-range' submission

- Assessment to demonstrate Universal Design for Learning principles

- Use consistent language across rubrics

- Embed hyperlink to Academic Support Office video resources covering referencing, time management, using evidence in assessment tasks, researching

- Opt-in simple post assessment survey for unit quality assurances.

- Refine assessment for quality

- Clearly defined assessment rubrics 


\section{Central Concept}

8. Scaffold work to meet AQF expectation requirements of learning to support students in their first years. Ensuring unit work is pitched to the expected level of student abilities.

9. Provide collective feedback to all students on how to improve on their assessments.

10. Map first year unit assessment due dates with other units, to enable students to better manage their time.

11. Creating an overt UC presence and approachability within the unit.

12. Create module reflection points and establish clear learning goals for each topic

\section{To appear in your unit}

- UDL - Heavy Scaffolding of a learning and assessment requirements.

- $\mathrm{AQF}$ learning language:

○ 100 level units - Remembering, understanding

○ 200 level units - Analysing, applying

○ 300 level units - Evaluating, creating

- Scaffolding Frameworks

- Use of 'markers reports' e.g. What a 'high-range' / 'mid-range' / 'low-range' submission looks like. The qualities of each band. This also helps reflective practice for unit writers/ co-ordinators.

- Global feedback on what could be better for the next assessment - highlight common mistakes.

- UCs to compile a short list of dot points summarising the cohort's efforts post each assessment performance

- $\quad$ Set dates with reasonable lead-in times to complete assessments.

- Use of Module Screen casting OR Welcome videos

- Module Zoom sessions for teaching modules 1-8

- A welcome video showing the face only is fine, but when it gets to the substance of the unit, a screen-cast (which can also show the lecturers face on a small window if required) that demonstrates exactly where to go and what to do, as shown by verbal description of clicks on the Moodle interface is what is required.

- Video connection with students that highlight what they've learned that week, what they will learn next week, and what they can do to best prepare.

- Use methods to reduce queries from students eg weekly announcements, reminding students of assessment requirements, FAQs

- Create a timetable so students know when you will be working on queries, and they can immediately ask you questions - 'Scheduler'

- All student queries go through SRM instead of email

- Offer a minimum of one live Q\&A sessions - Zoom

- Respond to all Moodle posts as soon as possible, but in a maximum of 24 hours. Tutors to work out with their UC re online staffing to assure timely online responses

- $\quad$ Provide opportunities for student-led forums, FAQ, chatbot

- Use of accessible language for first year students

- Being available does not necessarily equate to being approachable

- Announcements of reflection and learning goals through video

- Screencast

○ Asynchronous videos not recordings of tutorials 


\section{Central Concept}

13. Consistency of Moodle, teaching, presentation, location of items, structure, nomenclature

14. Access prior learning on a collaborative introduction activity

15. Distribution of Student Achievement Certificates (SACs) and a Certificate of Achievement as part of the Dean's Honour Roll

\section{To appear in your unit}

- 'Modules' encompass the central concept or theme of the learning.

- Learning is delivered via a series of 'Topics' to cover the concept of what is being taught.

- Provide a ‘to-do' scaffold explanation STYLE GUIDE pdf of major points of the new look Moodle site.

- Seamless navigation - units should contain intuitive navigation

- Embedded internal ‘autolinking' (and external) where appropriate

- Introduction tasks that create collaboration without having to have previously engaged with the unit work.

- Use prior knowledge of schools and teaching to create a community of practice.

- $\quad \mathrm{SAC}-$ For students that achieve a Distinction or HD in the unit as the final mark

- Dean's Honour Roll - For students that achieve a GPA over the year of 6.0 and above

\subsection{Final Interview}

Following the development of the signature pedagogy, UCs were responded to a number of prompts provided by email. Following analysis of the data, the following key findings were made.

\subsubsection{Benefits of the CSSP Project}

The primary benefit of the CSSP project that UCs described was in relation to the opportunity to see how other UCs engaged with their students and the techniques used to present their units in Moodle.

- Having an opportunity to see how other UC's organise their units was powerful.

- I did find being able to have a look at other units insightful and did get some ideas from this.

- Learning from the work of others.

- The biggest impact has been around finding new ways to engage students through observing the work of others.

\subsubsection{Communication with Students}

While UCs did not identify any substantial change in the way they viewed and communicated with students, they did describe benefits from having the opportunity to consider who their students were in terms of their background and how this might influence how they engaged with them.

- No change. It did confirm that what I am doing is actually Ok.

- As a new staff member, the CSSP training provided be a broader view of our student cohort backgrounds and the impact that these demographics can have on the student experience and retention.

- The biggest impact has been around finding new ways to engage students through observing the work of others. There has not been a shift in my thinking per se but rather a consolidation and extension of ideas.

- There has not been a shift in my think per se but rather a consolidation and extension of ideas.

Another key benefit identified was the opportunity to learn about new technological techniques available to engage students online. A member of the training team was a Faculty Learning Designer (FLD) and the benefits of being able to work with him on an ongoing basis were described.

- More powerful though was being introduced to technologies that I can use to make the lesson design theories related to differentiation that I teach in my units a reality in my units. This will enable me to model what is taught, which I have always found difficult in the online environment - this has 
always been a point of tension in my teaching in the past. [FLD's] workshops on HP5 were transformative for me.

- I am also am keen to explore the tools in Moodle, as presented by [FLD], and the pedagogical strategies they may afford.

- HP5 interactive activities for each unit - need to chat to [FLD]. Bring more consistency across my units in activities, placement of things, etc

- Working with colleagues and access to their units - this is something that could be built on and developed. [FLD]!!!!!!

\subsubsection{Barriers to CSSP Involvement}

There was no barrier described commonly by UCs. Two UCs identified that a lack of time may challenge engagement with the project requirements. A second barrier was identified as the use of outdated theories with which to frame the intervention training.

- Some of the issues with the project relate to tension amongst participants as to their views on the underlying theories used to frame the project, and the way this worked to slow some of the progress.

- I would like to have had my thinking challenged a little more. The theories that were presented were not new (actually they are quite old) and this did put me on the back foot to start with.

\section{Conclusion}

This paper has described the process by which a regional university has developed a signature pedagogy and integrated support model to enhance the experience of first-year students transitioning into the SOE. The process has provided UCs with the opportunity to have a voice in the process of change in relation to their academic role and pedagogical practices as the CSSP progresses. This approach has supported UCs in their engagement with the project and no substantial barriers to implementation have been identified to date.

The findings from the data analysis and the engagement of participants with the project indicated that the academics involved were open to engage with the project and to potentially develop innovative pedagogical approaches to working with first year students. The initial data collection indicated that there was a lack of a consistent approach to the commencement of teaching with first year students and limited engagement by UCs to prepare themselves to understand their students on an individual basis. This is, perhaps, due to the challenges associated with achieving this with a high proportion of students who study online. No substantial barriers were encountered during the initial training and first trimester of implement the signature pedagogy and participants identified a range of benefits from their involvement in the project.

One aspect that should also be considered in the professional development (PD) of university academics is their ongoing commitment to the process over time. Weuffen, Andrews, and Roberts (2020) demonstrated in a study at a similar regional Australian university that the initial enthusiasm for PD by academics reduces substantially within six months of initial engagement. This area will be examined in future research in this project.

It is evident that the opportunity for UCs to engage with each other and with an expert who can support them through technological changes were highly valued. The project has developed a signature pedagogy that has been approved for use within the SOE. The impact of the new approach will be evaluated and reported in a subsequent publication. In particular, the way in which UCs implement the signature pedagogy within their units, both in terms of what is offered in Moodle and the manner in which they engage with students, will be investigated.

\section{References}

Andrews, T., \& Tynan, B. (2012). Distance learners: Connected, mobile and resourceful individuals. Australasian Journal of Educational Technology, 28(4), 565-579. https://doi.org/10.14742/ajet.828

Australian Institute for Teaching and School Leadership. (2020). Australian Professional Standards for Teachers. Retrieved from https://www.aitsl.edu.au/teach/standards

Axinn, W., \& Pearce, L. (2006). Mixed method data collection strategies: Cambridge University Press. https://doi.org/10.1017/CBO9780511617898

Bandura, A. (2001). Social cognitive theory of mass communication. Media Psychology, 3(3), 265-299. https://doi.org/10.1207/S1532785XMEP0303_03 
Barnes, S., Macalpine, G., \& Munro, A. (2015). Track and connect: Enhancing student retnetion and success at the University of Sydney. A Practice Report. International Journal of the First Year in Higher Education, 6(1), 195-202. https://doi.org/10.5204/intjfyhe.v6i1.266

Baumeister, R., \& Leary, M. (1995). The need to belong: Desire for interpersonal attachments as a fundamental human motivation. Psychological Bulletin, 117(3), 497-529. https://doi.org/10.1037/0033-2909.117.3.497

Bolton, E. (2016). Ideas, concerns and expectations - a "whole of institution" approach to navigating transitions and mapping the journey. Retrieved from http://ubir.bolton.ac.uk/1053/1/McIntosh\%2C\%20Dr.\%20Emily\%20Ideas\%20concerns\%20expectations\%20ST ARS\%20CONF\%202016.pdf

Brown, T. (2020). An age of endarkenment? Can adult education still make a difference? Australian Journal of Adult Learning, 60(1), 8-21.

Burke, P. (2006). Identity change. Social Psychology Quarterly, 69(1), 81-96. https://doi.org/10.1177/019027250606900106

Debenham, J., \& May, J. (2005). Making connections: A dialogue about learning and teaching in a tertiary enabling program. Australian Journal of Adult Learning, 45(1), 82-104.

Edwards, D., \& McMillan, J. (2015). Completing university in a growing sector: Is equity an issue? Retrieved from https://research.acer.edu.au/cgi/viewcontent.cgi?article=1045\&context=higher_education

Falasca, M. (2011). Barriers to adult learning: Bridging the gap. Australian Journal of Adult Learning, 51(3), 583-590.

Farr-Wharton, B., Charles, M., Keast, R., Woolcott, G., \& Chamberlain, D. (2017). Why lecturers still matter: The impact of lecturer-student exchange on student engagement and intention to leave university prematurely. Higher Education, 75(1), 167-185. https://doi.org/10.1007/s10734-017-0190-5

Fraser, S., Beswick, K., Penson, M., Seen, A., \& Whannell, R. (2019). Cross faculty collaboration in the development of an integrated mathematics and science initial teacher education program. Australian Journal of Teacher Education, 44(7), Article 5. https://doi.org/10.14221/ajte.2019v44n7.5

Gasiewski, J., Eagan, M., Garcia, G., Hurtado, S., \& Chang, M. (2012). From gatekeeping to engagement: A multicontexual, mixed method study of student academic engagement in introductory STEM courses. Research in Higher Education, 53(2), 229-261. https://doi.org/10.1007/s11162-011-9247-y

Grebennikov, L., \& Shah, M. (2012). Investigating attrition trends in order to improve student retention. Quality Assurance in Education, 20(3), 223-236. doi: https://doi.org/10.1108/09684881211240295

Hall, T., Meyer, A., \& Rose, D. (2012). Universal design for learning in the classroom: Practical applications: Guilford Press.

Kahu, E., \& Nelson, K. (2018). Student engagement in the education interface: Understanding the mechanisms of student success. Higher Education Research \& Development, 37(1), 58-71. https://doi.org/10.1080/07294360.2017.1344197

Kahu, E., Stephens, C., Leach, L., \& Zepke, N. (2015). Linking academic emotions and student engagement: Mature-aged distances students' transition to university. Journal of Further and Higher Education, 39(4), 481-497. https://doi.org/10.1080/0309877X.2014.895305

Kelley, H., \& Michaela, J. (1980). Attribution theory and research. Annual Review of Psychology, 31(1), 457-501. https://doi.org/10.1146/annurev.ps.31.020180.002325

Kift, S., \& Moody, K. (2009). Harnessing Assessment and Feedback in the First Year to Support Learning Success, Engagement and Retention. Paper presented at the ATN Assessment Conference, RMIT University, Melbourne, Australia.

Kift, S., Nelson, K., \& Clarke, J. (2010). Transition pedagogy: A third generation approach to FYE: A case study of policy and practice for the higher education sector. The International Journal of the First Year in Higher Education, 1(1), 1-20. https://doi.org/10.5204/intjfyhe.v1i1.13

Li, I., \& Carroll, D. (2020). Factors influencing dropout and academic performance: An Australian higher education equity perspective. Journal of Higher Education Policy and Management, 42(1), 14-30. https://doi.org/10.1080/1360080X.2019.1649993 
McMillan, J. (2005). Course change and attrition from higher education (Vol. LSAY Research Report Number 39). Retrieved from https://research.acer.edu.au/cgi/viewcontent.cgi?article=1042\&context=lsay_research

Moore, M. (1993). Theory of transactional distance. Theoretical Principles of Distance Education, 1, 22-38.

Posselt, J. (2016). Inside graduate admissions: Merit, diversity, and faculty gatekeeping. Cambridge MA: Harvard University Press. https://doi.org/10.4159/9780674915640

Richardson, S. (2011). Uniting teachers and learners: Critical insights into the importance of staff-student interactions in Australian university education: AUSSE Research Briefing v.12 ACER.

Roberts, P., Boldy, D., \& Dunworth, K. (2015). The views of international students regarding university support services in Australia: A case study. International Education Journal: Comparative Perspectives, 14(3), 122-137.

Schunk, D., \& Mullen, C. (2012). Self-efficacy as an engaged learner Handbook of research on student engagement (pp. 219-235). Boston, MA.: Springer. https://doi.org/10.1007/978-1-4614-2018-7_10

Stallman, H. (2010). Pscyhological distress in university students: A comparison with general population data. Australian Psychologist, 45(4), 249-257. https://doi.org/10.1080/00050067.2010.482109

Stets, J., Burke, P., Serpe, R., \& Stryker, R. (2020). Getting identity theory (IT) right Advances in group processes: Emerald Publishing Limited. https://doi.org/10.1108/S0882-614520200000037007

Stone, C., \& Springer, M. (2019). Interactivity, connectedness and 'teacher-presence': Engaging and retaining students online. Australian Journal of Adult Learning, 59(2), 146-169.

Stringer, E. (2008). Action research in education. Upper Saddle River, NJ.: Pearson Prentice Hall.

Stryker, S., \& Burke, P. (2000). The past, present and future of an identity theory. Social Psychology Quarterly, 63, 284-297. https://doi.org/10.2307/2695840

Thomas, L. (2012). Building student engagement and belonging in Higher Education at a time of change. Paul Hamlyn Foundation, 100, 1-99.

Thomas, T., Jacobs, D., Lurley, L., Martin, J., Maslyuk, S., Lyall, M., \& Ryan, M. (2018). Students' perspectives of early assessment tasks in their first-year at university. Assessment \& Evaluation in Higher Education. https://doi.org/10.1080/02602938.2018.1513992

Usher, E., \& Pajares, F. (2008). Sources of self-efficacy in school: Critical review of the literature and future directions. Review of Educational Research, 78(4), 751-796. https://doi.org/10.3102/0034654308321456

Weuffen, S., Andrews, T., \& Roberts, K. (2020). Promoting quality learning and teaching pedagogy: Evaluating a targeted localised academic inducatino program (AIP) for the impact on continuing professional development. Australian Journal of Adult Learning, 60(2), 245-267.

Whannell, P., Whannell, R., \& Allen, B. (2012). Investigating the influence of teacher strategies on academic self-efficacy and study behaviour of students in a tertiary bridging program. Australian Journal of Adult Learning, 52(1), 39-65.

Whannell, R., \& Whannell, P. (2015). Identity theory as a theoretical framework to understand attrition for university students in transition. Student Success, 6(2), 43-52. https://doi.org/10.5204/ssj.v6i2.286

\section{Copyrights}

Copyright for this article is retained by the author(s), with first publication rights granted to the journal.

This is an open-access article distributed under the terms and conditions of the Creative Commons Attribution license (http://creativecommons.org/licenses/by/4.0/). 